\title{
Electronic CONTrol System Of Rotating AXes of LONG BASED ROAD TRAIN
}

\author{
Alexander Abramov ${ }^{\mathrm{a}}$, Igor Blyankinshtein ${ }^{\mathrm{b}}$ \\ ${ }^{a}$ Novgorod State University, ul. B. St. Petersburgskaya, 41, Veliky Novgorod, 173003,Russia \\ ${ }^{b}$ Siberian Federal University, prospekt Svobodny, 79, Krasnoyarsk, 660041, Russia
}

\begin{abstract}
In the article the description of the developed electronic control system of rotary axes of the long road train is presented. The electrohydraulic control system contains two control paths: the main, the signals fulfilling the operating influence set by the driver in the form of an angle of rotation of a steering wheel and correcting, using as the setting parameters from feedback sensors: road speed of the road train, side acceleration of the semi-trailer and its angular vertical axis speed. The description of mathematical model of the of long road train with the rotary axes including linearized singletrack is provided. The algorithm of management of an adaptive control system of rotary axes of the long road train with the correcting control path is developed. The use of a ECS of rotary axes with the correcting control path optimizing the offset value of the cart of the semi-trailer guidepath to of a basic point of the tractor allows to reduce it to $0.1 \mathrm{~m}$.
\end{abstract}

Keyword: a road train; control system; block schematic diagram; mathematical model; algorithm of management; modeling; guidepath
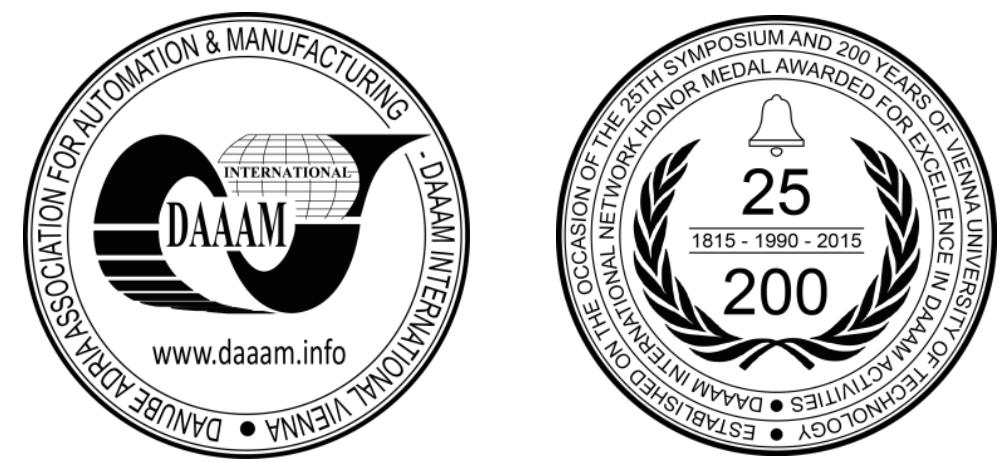

This Publication has to be referred as: Abramov, A[lexander] \& Blyankinshtein, I[gor] (2016). Electronic Control System of Rotating Axes of Long Based Road Train, Proceedings of the 26th DAAAM International Symposium, pp.0810-0817, B. Katalinic (Ed.), Published by DAAAM International, ISBN 978-3-902734-07-5, ISSN 1726-9679, Vienna, Austria

DOI:10.2507/26th.daaam.proceedings.113 


\section{Introduction}

Nowadays long road trains are used to deliver long length and large-size cargos. In order to meet the regulated maneuverability indicators the semi-trailer of the road train has to be equipped with rotary axes and the corresponding control system [1,2].

The analysis of control systems of semi-trailers of long road trains proved hydro-volume steering units to be most generally used on the roads [3].

Electronic control units help to secure required rotary truck control logic of a semi-trailer, as well as make it possible to use a jack-knifing angle and a steering angle of a tractor as a specifying parameter [4,5].

Besides, according to calculations made by TRIDEC company the use of a control system of rotary axes in a road train allows to reduce tires wear by $66 \%$ [6].

The control system of ETS of VSE (Holland) can be an example of such system [7]. In the article the description of the developed electronic control system of rotary axes of the long road train is presented. The electrohydraulic control system contains two control paths: the main, the signals fulfilling the operating influence set by the driver in the form of an angle of rotation of a steering wheel and correcting, using as the setting parameters from feedback sensors: road speed of the road train, side acceleration of the semi-trailer and its angular vertical axis speed.

The description of mathematical model of the of long road train with the rotary axes including linearized single-track is provided.

The algorithm of management of an adaptive control system of rotary axes of the long road train with the correcting control path is developed. Criterion of optimization is the offset value of a real cart pathway of a semi-trailer of the road train to nominal trajectory of the tractor set by the operating influence of the driver.

The use of a ECS of rotary axes of the of long-based road train with the correcting control path optimizing the offset value of the cart of the semi-trailer guide path to a basic point of the tractor allows reduction to $0.1 \mathrm{~m}$ that significantly improves vehicle steerability on the road and increases traffic safety, especially in the conditions of intensive traffic flows.

\section{Subject of research}

In previous studies $[8,9,10]$ the authors used one-channel steering system in which thejack-knifing angle was used as a master value and steering values were set for steady-state in circular motion of the road train. Whereas the maximum offset value of the tractor and the cart is observed at transition paths i.e. at unsteady-state motion [11].

An electronic control system rotary axes long tractor-trailer being proposed, structural scheme of which is shown in fig. 1, contains two control channels: the main one, responding to driver's control action in a form of steering angle $\alpha_{p \kappa}$, and the corrective one, using signals from feedback sensors as specifying parameters: driving speed of the train $v_{x}$, side acceleration of a semitrailer $j_{y}$, and its angular speed in relation to vertical axis $\omega_{z}$.Control impact in the main channel in a form of steering angle $\alpha_{p \kappa}$ using a mathematical model of nominal behavior of trains converts into a control signal of control system rotary axes of a semitrailer. This nominal mathematical model calculates movement parameters of the train corresponding to its movement in ideal conditions on a road with a high adhesion coefficient. The second control channel is a corrective one. The mathematical model uses signals from feedback sensors as specifying parameters $v_{x}, j_{y}, \omega_{z}$ and calculates parameters of actual behavior of the train.

Calculation results of nominal and actual parameters are compared, and with the help of logic elements corrective actions are defined in a form of $\pm d \alpha_{3}$ - steering axis rotation angle of a semitrailer.

An optimization criterion used in the control system is a guidepath motion value of a semi-trailer cart in relation to the guidepath of a trailer back axis.

The control system of long based tractor-trailer contains a sensor of steering angle of the train and a sensor of jackknifing angle, mechanically connected with a tractor bolster, as specifying parameters.

The control system of long based tractor-trailer changes functional relation between steering angle of the train and steering axis rotation angle of the semi-trailer depending on a semi-trailer wheel base, when using telescoping semitrailer frame. 


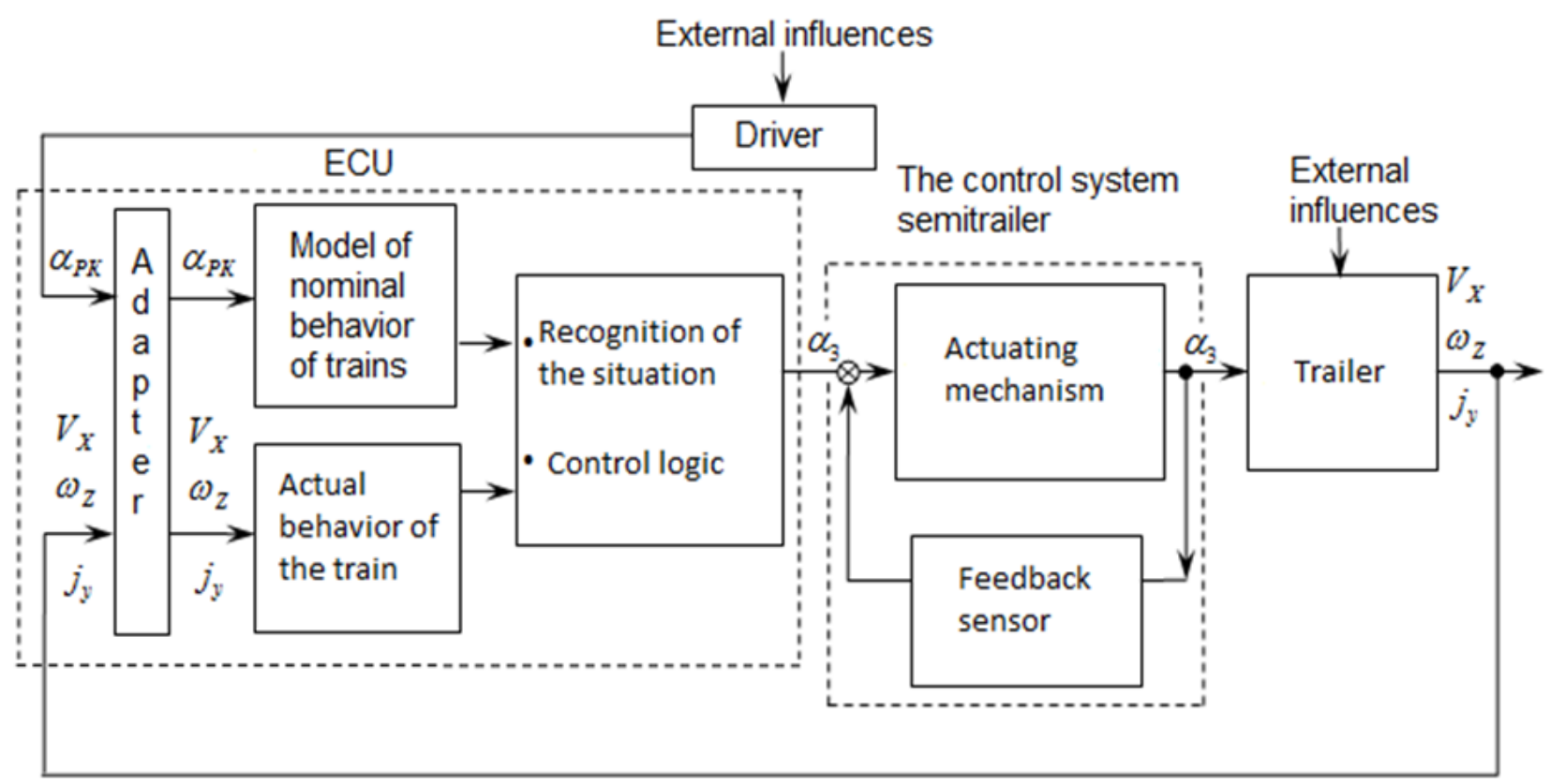

Fig. 1. Structural scheme of a train control system.

The sensor of a semi-trailer wheel base registers actual value of a semi-trailer base and, depending on its meaning, ECU selects an optimum functional relation between steering angle of the train and steering axis rotation angle of a semi-trailer among the tabulated values, in order to secure optimum values of train maneuverability.

The performance part of the control system is implemented in a form of an electrohydraulic drive [12]. Fig. 2 shows a scheme of an electronic control system.

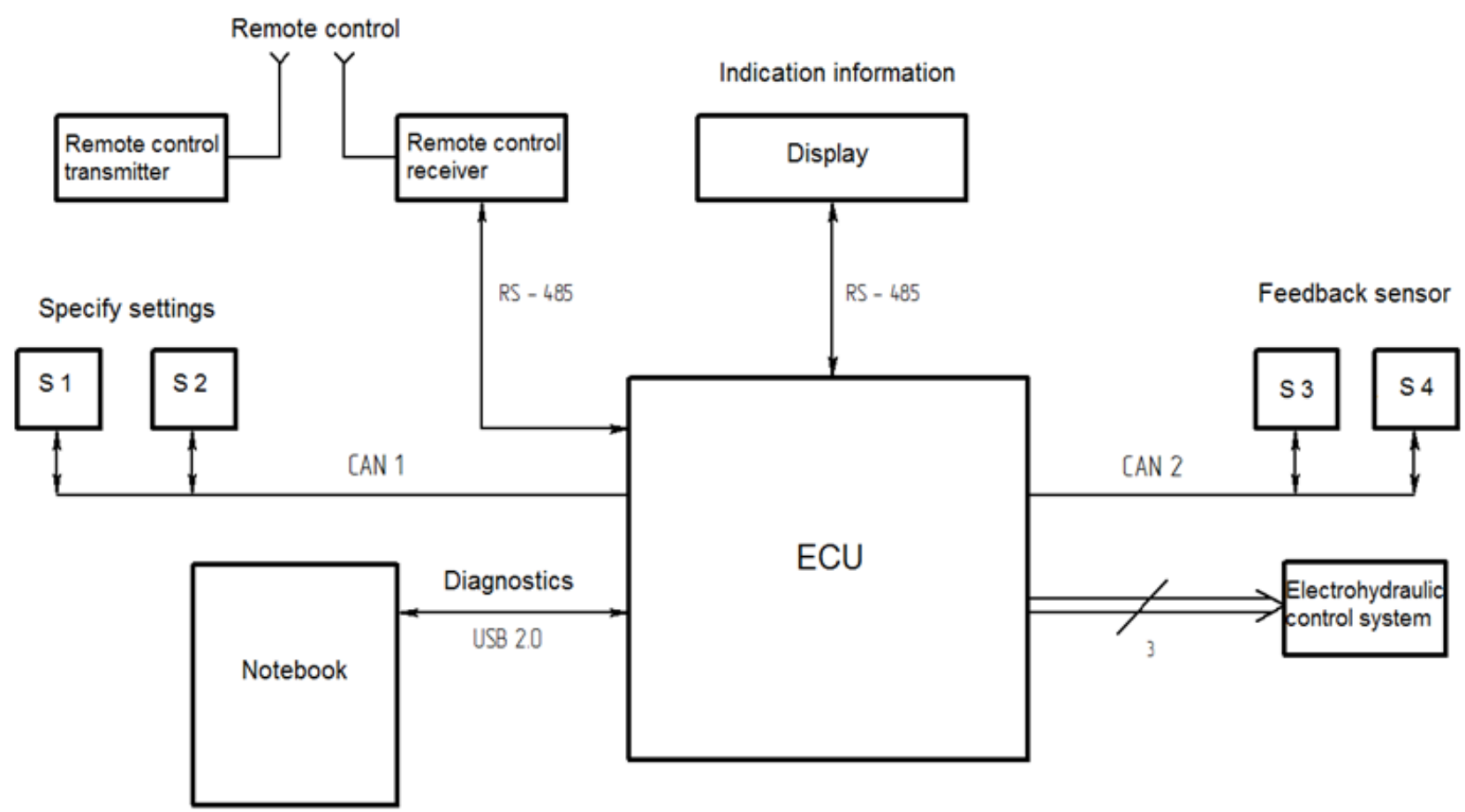

Fig. 2. The scheme of an electronic control system.

The functional scheme of which is given in fig.3. 


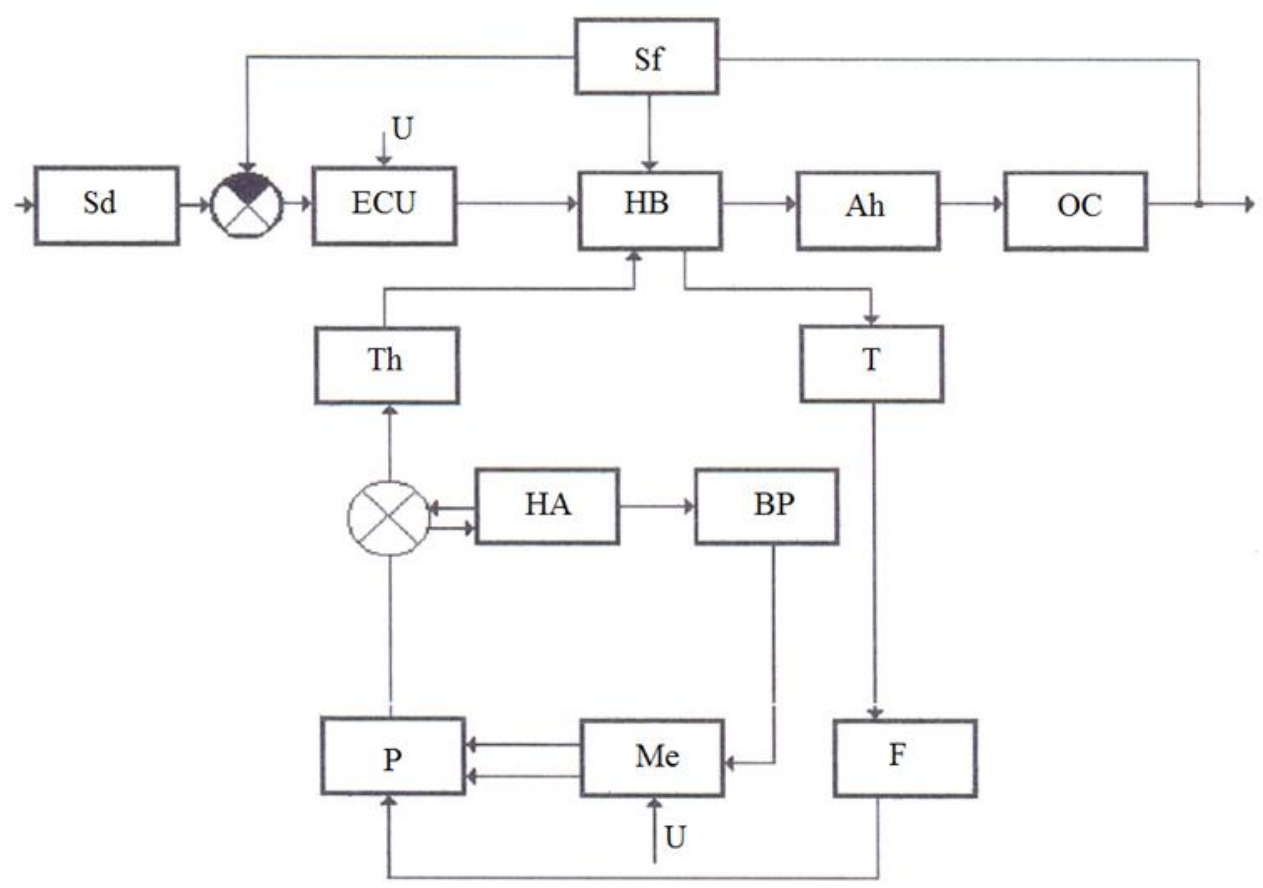

Fig. 3. The functional scheme of an electrohydraulic drive.

$\mathrm{Sd}$ - defining sensor; ECU - ; HB - hydraulic booster; $\mathrm{S}_{\mathrm{f}}$ - feedback sensor; Ah - hydraulic actuator; OC - control object; Th - hydraulic throttle; HA - hydraulic accumulator; BP - block maintain the desired fluid pressure; $\mathrm{P}$ - pump; $\mathrm{Me}$ - electric motor; $\mathrm{F}$ - filter.

Moreover, the electronic control system has a manual control option and contains a manual control unit connected with ECU via a radio channel. Transfer to manual control is realized from driver's cab only when it is necessary to rotate steering semitrailer axes regardless of steering angle of the train, for example, when maneuvering in a limited space.

Whereby, rotation direction of steering axes of the semitrailer and a truck can be one-way, which enables plane-parallel motion of the train sideward.

When switching to automatic control, steering axes of the semitrailer are automatically installed in accordance with a steering angle of the train. Availability of a centering device on steering axes makes it possible for a system to return steering axes to their neutral position with subsequent blocking in case of a failure.

An electronic control unit controls the work of electronic subsystems. All sensors of the control system are connected with the electronic control unit via CAN bus. CAN bus enables usage in the control system of signals from other systems' sensors. For example, a steering angle sensor from ESP system and steering wheel speed sensor from ABS system are used. In ECU self-testing of control system is implemented.

\section{Mathematical model of the train.}

Dynamics of nonlinear motion of the train has been analyzedin order to improve a control algorithm and assess influence of various design factors on maneuverability values.

A mathematical model consists of two joints - a tractor and a semitrailer with steering axes.

Every joint has three degrees of freedom: linear longitudinal and cross movements on a road, and rotation of the joints in relation to their vertical axes [13].

There is a series of admissions used to simplify a mathematical model:

- if the train moves on a horizontal absolutely smooth surface, vertical motions of its joints are not taken into account;

- the train moves at a constant speed;

- all centers of gravity of train joints, as well as pre-spring masses, are located in a vertical plane of their symmetry;

- there is a backlash-free mesh between the trailing joint and the tractor;

- joints of the train and their structures are taken as rigid. 
Fig.4. shows a calculation scheme of mathematical model used for a four-axis train.

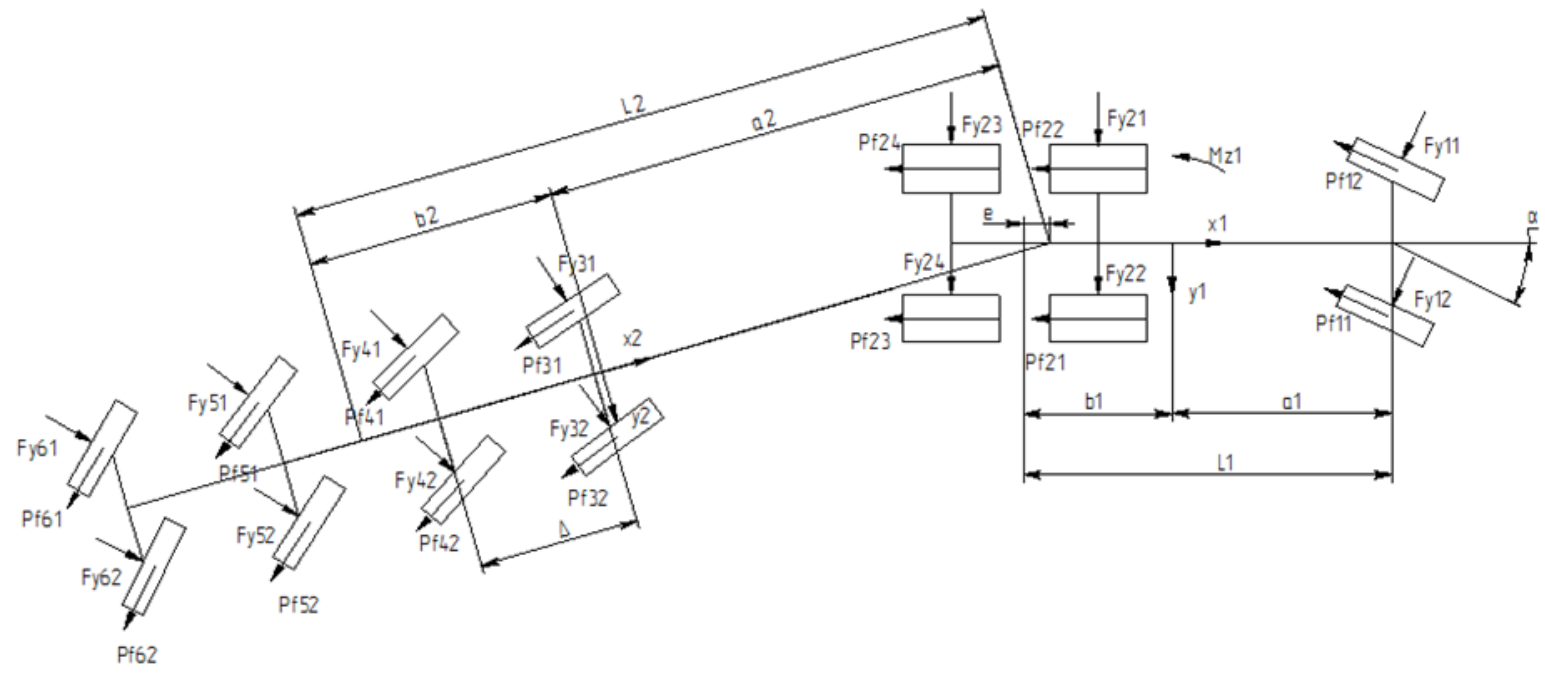

Fig. 4. The sScheme of mathematical model for a four-axis train.

In order to simplify a mathematical model being developed, we consider a single-track model. Fig. 5 shows the scheme of a single-track train model.

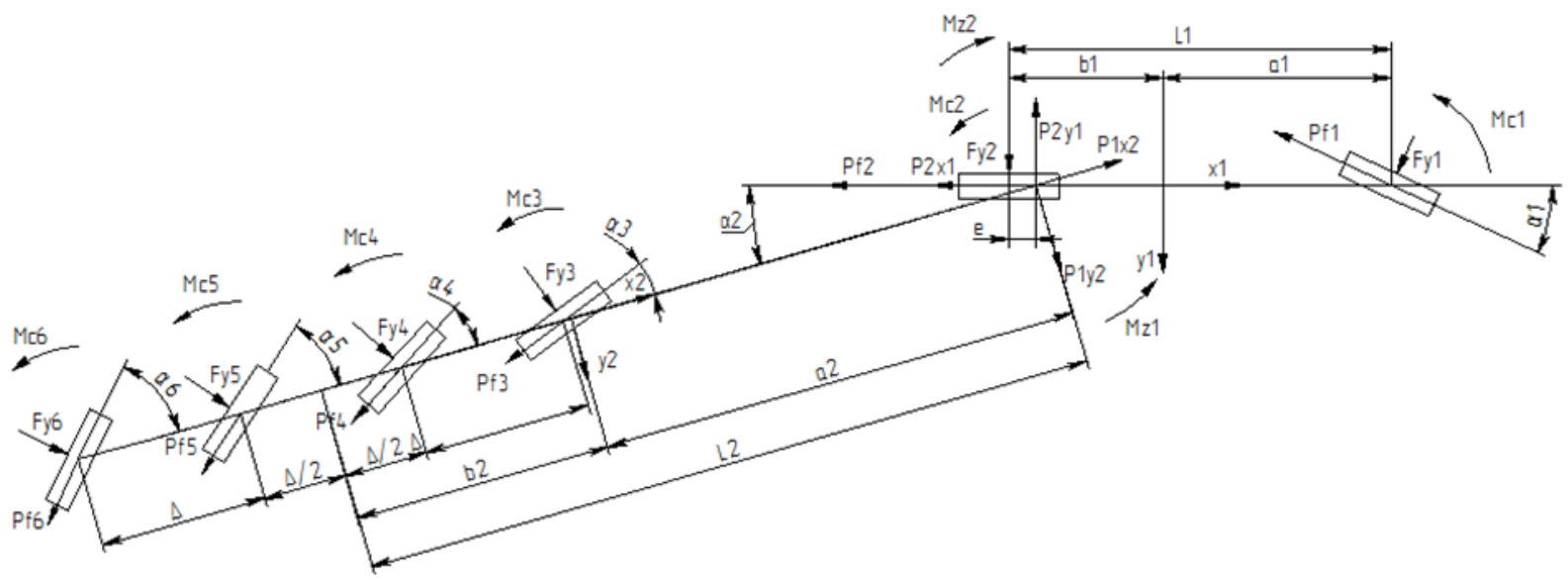

Fig.5. the scheme of a single-track train model.

We form differential equations of nonlinear train motion.

- tractor

$V_{x 1}=$ const $; \quad \Sigma P_{i x 1}=0$

$m_{1} j_{y 1}=F_{y 1} \cos \alpha_{1}+F_{y 2}-P_{f 1} \sin \alpha_{1}-P_{2 y 1}$

$J_{z 1}^{\circ} \omega_{1}=a_{1} F_{y 1} \cos \alpha_{1}-\left(b_{1}-\Delta l_{T 2}\right) F_{y 2}-M_{T \Sigma}+$

$+\left(b_{1}-e_{1}\right) P_{2 y 1}-a_{1} P_{f 1} \sin \alpha_{1}+M_{c 1}+M_{c 2}-M_{M_{\tau 2}}$

- $\quad$ semitrailer

$m_{2} j_{x 2}=P_{1 x 2}-F_{y 3} \cos \alpha_{3}-F_{y 4} \cos \alpha_{4}-F_{y 5} \cos \alpha_{5}$

$m_{2} j_{y 2}=P_{1 y 2}-F_{y 3} \sin \alpha_{3}-F_{y 4} \sin \alpha_{4}-F_{y 5} \sin \alpha_{5}$ 
$J_{z 2}^{\circ} \omega_{2}=a_{2} P_{1 y 2}+\left(b_{2}-1,5 \Delta\right) P f_{3}+\left(b_{2}-\Delta / 2\right) P f_{4}+\left(b_{2}+\Delta / 2\right) P f_{5}+\left(b_{2}+\right.$

$1,5 \Delta) P f_{6}+M_{z 1}-M_{\mathrm{c} 3}-M_{\mathrm{c} 4}-M_{\mathrm{c} 5}-M_{c 6}-M_{T \Sigma}$

$m_{i}$ - pre-spring mass of joint $\mathrm{i}, \mathrm{kg}$;

$J_{z i}^{\circ}$ - joint inertia in relation to a vertical axis running across its center of gravity, $\mathrm{kg} . \mathrm{m} / \mathrm{s}$;

$\omega, \omega_{i}$ - angle speed and acceleration of joint $\mathrm{i}, 1 / \mathrm{s}$;

$\alpha_{1}$ - tractor steering angle, radian;

$\alpha_{2}$-jack-knifing angle, radian;

$\alpha_{i}-$ axis i rotation angle of the semitrailer, radian;

$F_{y i}$ - total cornering force influencing both wheels of axis $\mathrm{j}, \mathrm{kN}$;

$P_{f 1}-$ wheel rolling resistant force of axis $\mathrm{j}, \mathrm{kN}$;

$P_{k x(k \pm 1)^{-}}$projection of exchange forces of the train on the corresponding axis;

$M_{c i}$ - total tire stabilizing moment influencing wheels of axis $\mathrm{j}$;

$M_{T \Sigma}$ - total resistance to wheel rotation moment of the semitrailer;

$a_{i} ; b_{i^{-}}$coordinates of the joint center of gravity;

$M_{z 1}$ - moment of friction in the truck-tractor;

$e$ - displacement of the truck-tractor;

$L_{1}$ and $L_{2}-$ joint (tractor, semitrailer) base;

$\Delta$ - center-to-center distance between semitrailer wheels.

In case of stochastic external impacts and side accelerations of maximum $0.4 \mathrm{~g}$, as well in case of wheel sliding and other less significant admission corresponding to normal operational conditions, lateral reactions and their moments can be expressed in a simple linear dependence.

$F_{y i}=-K_{\delta} \delta_{i}$

$M_{c i}=-C_{\delta i} \delta_{i}$

W where $\delta_{i}$ - slip angle of axis $\mathrm{i}$;

$K_{\delta}$ - cornering power;

$C_{\delta i}$ - angle tire roll rate.

Linearized equations describe nonlinear motion of the train in a road plane (XOY) and can be shown as a matrix

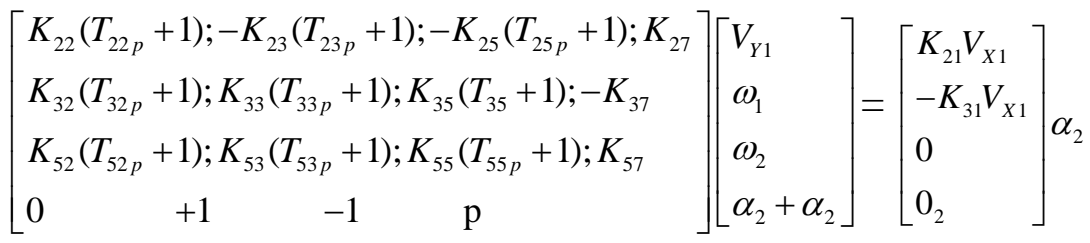

With the help of Cramer's rule this matrix provides transfer functions of parameters characterizing plane nonlinear motion of the train

$V_{Y 1}=\frac{D_{V Y 1}}{D_{0}} ; \quad \omega_{1}=\frac{D_{\omega 1}}{D_{0}} ; \quad \omega_{2}=\frac{D_{\omega 2}}{D_{0}} ;\left(\alpha_{2}+\alpha_{3}\right)=\frac{D\left(\alpha_{2}+\alpha_{3}\right)}{D_{0}}$

where:

$D_{0}$ - main determinant of a system of linearized equations, if their right parts equals to zero;

$D_{i}$ - determinant, resulting from $D_{0}$ substitution of the corresponding column I by the right part of the equations.

\section{Selection of laws controlling rotation of semitrailer axes}

In order to achieve required maneuverability properties of the train, there are determined control laws securing compliance with technical requirements concerning train flexibility within limited overall dimensions. The control laws were been selected based on analysis of simplified equations of train motionavailable.

$\omega \_(1)=K_{-} \omega 1 \alpha \_1$;

$\omega \_(2)=K \_\omega 2\left(\alpha \_2+\alpha \_3\right)$; 
$\alpha \_2=\omega \_1-\omega \_2$.

These equations help to determine rotation angle of steering axes of the semitrailer

$\alpha_{3}=K_{\alpha 2} \alpha_{1}-\left(T_{\alpha 2}+1\right) \alpha_{2}$

where:

$K_{\alpha 2}=\frac{L_{2}^{\Pi}}{L_{x 1}^{\Pi}}$

$T_{\alpha 2}=\frac{L_{2}^{\Pi}}{V_{x 1}^{\Pi}}$

As a result we will obtaint a law controlling rotation of the semi-trailer cart from jack-knifing angle $\alpha_{2}$. This law is as follows:

$\alpha_{3}=\frac{1}{T_{\alpha 2} p+1} \alpha_{2}$

For automatic control systems of electrohydraulic type this law workswith transfer coefficientKП= 1 and time constant

$T_{\Pi}=T_{\alpha}=L_{2} / V_{X 1} K_{\Pi}$

Whereby, it shall be taken into account that choice of a time constant $T_{\Pi}$ secures movement of the semi-trailer cart on the transfer track, while $K_{\Pi}$ is used for movement in a sector of stable circular movement.

In order to analyze maneuverability properties of the long based train, turnings around $90^{\circ}, 180^{\circ}$ and "resetting" mode with parameters $24 \mathrm{~m}$ x $2.5 \mathrm{~m}$ were chosen as the main motion regimes. An example of modeling results is shown in fig. 6

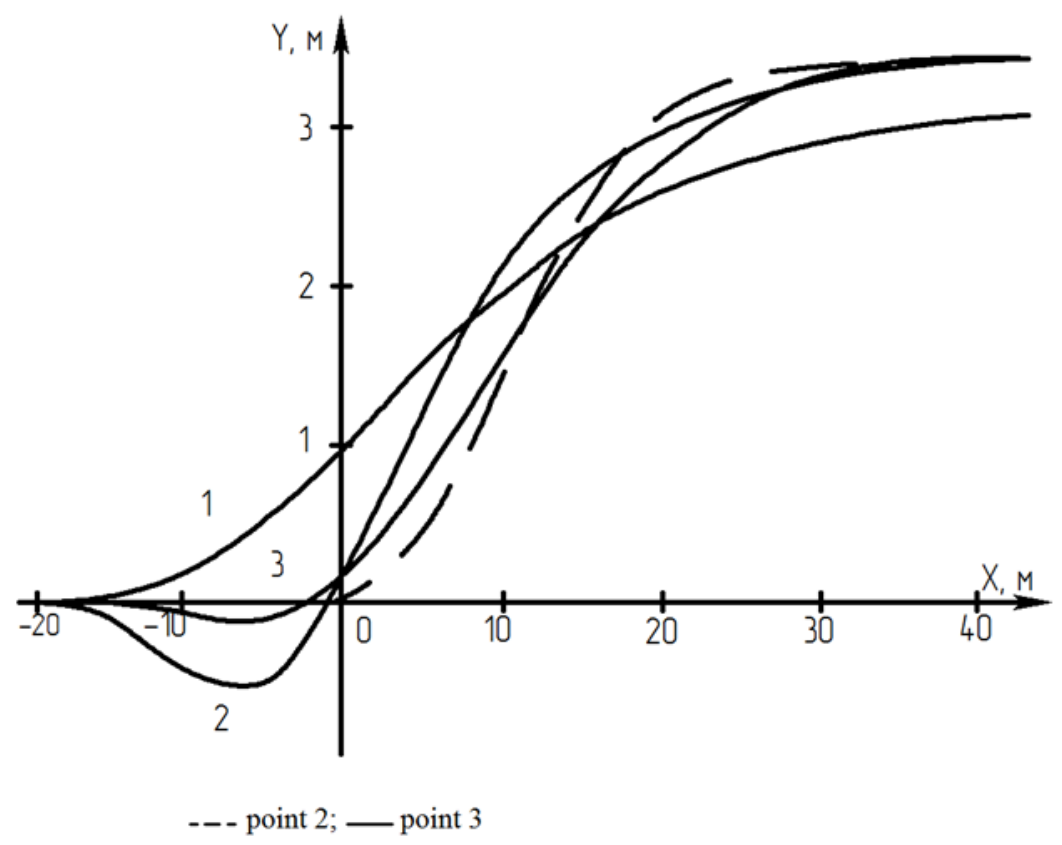

Fig. 6. The track of characteristic points of the train in case of completion maneuver $24 \times 3.5 \mathrm{~m} .1-\mathrm{K}_{\Pi}=0 ; 2-\mathrm{K}_{\Pi}=1$; $3-\mathrm{K}_{\Pi}=1, \mathrm{~T}_{\Pi}=2$.

\section{Conclusion}

Modern hydro-volume steering unit-based long based road trains as a rule lack maneuverability due to the offset value of the cart of the semi-displacement guide path 
The study of mathematical model of long based road trains with rotary axes provided a controlling mechanism of adaptive road train system with adjustable steering channel. The offset value of the cart axes to nominal guidepath of the train is considered a criteria of optimization in the steering system

The ESC with rotation axes in long based tractor-trailer with adjustable steering system which optimize the offset value of the rotary axes to basic point of the tractor allows to reduce it to $0.1 \mathrm{~m}$

In future ESC can be integrated into a system of longitudinal and lateral dynamic stability on the road and contribute to vehicle steerability on the road by increasing traffic safety, especially in the conditions of intensive traffic flows. In the perspective electronic control system rotary axes of long based tractor-trailer can be integrated into systems of a higher level.

\section{References}

[1] Anon, 'Transport Statistics Great Britain 2004'.30th edition, 2004, Department for Transport: London, UK.

[2] Zakin Ia.Kh. Maneuverability of the vehicle and road trains. M.:Transport, 1986. 136 p.

[3] Prem H, 'Performance Evaluation of the Trackaxle Steerable Axle System. Proc. 7th ISHVWD. 2002, Delft, The Netherlands.

[4] Sachno W.P., Poljakov W.M., Sharaj S.M. Improved maneuverability properties of the long based road trains by the use of the microprocessor control system semitrailer. - Abstracts of the All-Union Scientific Conference "The use of microprocessor technology in the control system of the vehicle.". - Minsk, 1988, pp.90-91.

[5] Gohring E et al, 'Optimisation of Manoeuvrability and Directional Stability of Commercial Vehicles by an Electronically Controlled All-Wheel Steering System’. SAE 945090. SAE Transactions, 1994. 103(2): p. $219-236$.

[6] TRIDEC Poduct Flyer.: http://www.tridec.nl/en/products/hydraulic-steering-systems.html

[7] ETS Trailer. VSE, https://www.v-s-e.com/uploads/documents/ets_trailer_nl_2009.pdf

[8] QiangWang, Masahiro Oya and Toshihiro Kobayashi. Adaptive Lane Keeping Control for Combination Vehicles Without Measurement of Lateral Velocity, AVEC '08 - 056, 20080456.

[9] B. A. Jujnovich1, A. M. C. Odhams, R. L. Roebuck, D. Cebon. Active Rear Steering Control of a Tractor - SemiTrailer, AVEC '08 - 142, 20080542.

[10] Usage of systematic multi-body equations of motion for the design of a nonlinear vehicle dynamics controller/Gunter Nitzsche, Klaus Röbenack, Sebastian Wagner, Stephan Zipser //Special Issue: 85th Annual Meeting of the International Association of Applied Mathematics and Mechanics (GAMM), Erlangen 2014; Editors: P. Steinmann and G. Leugering.Volume 14, Issue 1, pages 67-68, December $2014 . \quad-$ http://onlinelibrary.wiley.com/doi/10.1002/pamm.201410021/pdf

[11] Abramov A. M. Modeling of a control system for a roadtrain // Vestnik NovSU. Issue: Engineering sciences. 2014. № 75.V.1. P.49-53.The reference list 3 items, 6 fig.

[12] Dinca L., \& Corcau,J.I. Experimental Development and Numerical Simulation of an Electro-Hydraulic ServoActuator, Chapter 50 in DAAAM International Scientific Book 2013, pp. 831-848, B. Katalinic \& Z. Tekic (Eds.), Published by DAAAM International, ISBN 978-3-901509-94-0, ISSN 1726-9687, Vienna, Austria.

[13] M.Mitschke Dynamik der Kraftfahrzeuge. VDI - Buch, 2004, - 806 p. 